\title{
PERFORMANCE ANALYSIS OF A STEAM TURBINE POWER PLANT AT PART LOAD CONDITIONS
}

\author{
A. Sinan Karakurt ${ }^{* 1}$, Ümit Güneş ${ }^{1}$ \\ Keywords: Off design conditions, thermal efficiency, isentropic efficiency, power plant, steam turbine
}

\begin{abstract}
Power consumption highly increases which is related with the growing of the industrial plants and daily using. Increasing power demand can be supplied with building up more efficient plants or optimized old power plants. One of the most important items of a power plant is steam turbine which is designed according to defined parameters (inlet pressure and temperature, flow rates, outlet pressure and power) which also effect the dimensions and performance of the turbine. Turbine loses and irreversibilities are minimum and so efficiencies and power generation are maximum at design conditions. However, power plants always have to operate at off-design or partload conditions because of the changing of power demands and drop outs of the turbines and other items of the plants. In this study, it is aimed to analyses the isentropic efficiency of a high pressure steam turbine and thermal efficiency of power plant at different load conditions. Analyses showed that both steam turbines and power plant performance were reduced when the power plant operates at partial load conditions.
\end{abstract}

\section{INTRODUCTION}

Power consumption highly increases which is related with the growing of the industrial plants and daily using. Increasing power demand can be supplied with building up more efficient plants or optimized old power plants. The thermal efficiency depends on the all equipment (turbines, boilers, pump, etc.) performance so how the equipment are efficient thermal efficiency and cost are optimum. The most important items of a power plant are steam or gas turbines therefore their design and operating conditions are very important.

Steam turbine design is based on some characteristic features such as inlet pressure and temperature, flow rate, outlet pressure etc. and turbine geometry, dimensions and performance are defined with this characteristic features. Turbine loses and irreversibilities are minimum and performance and power generation are maximum at design conditions. However, a steam turbine does not always operate at design conditions because of changing of power demand and turbine loses and this means that it always operates lower efficiency. Estimating and defining of characteristics of steam turbines at off-design conditions have been studied since 1900 and today the studies are going on more different variables and modern tools.

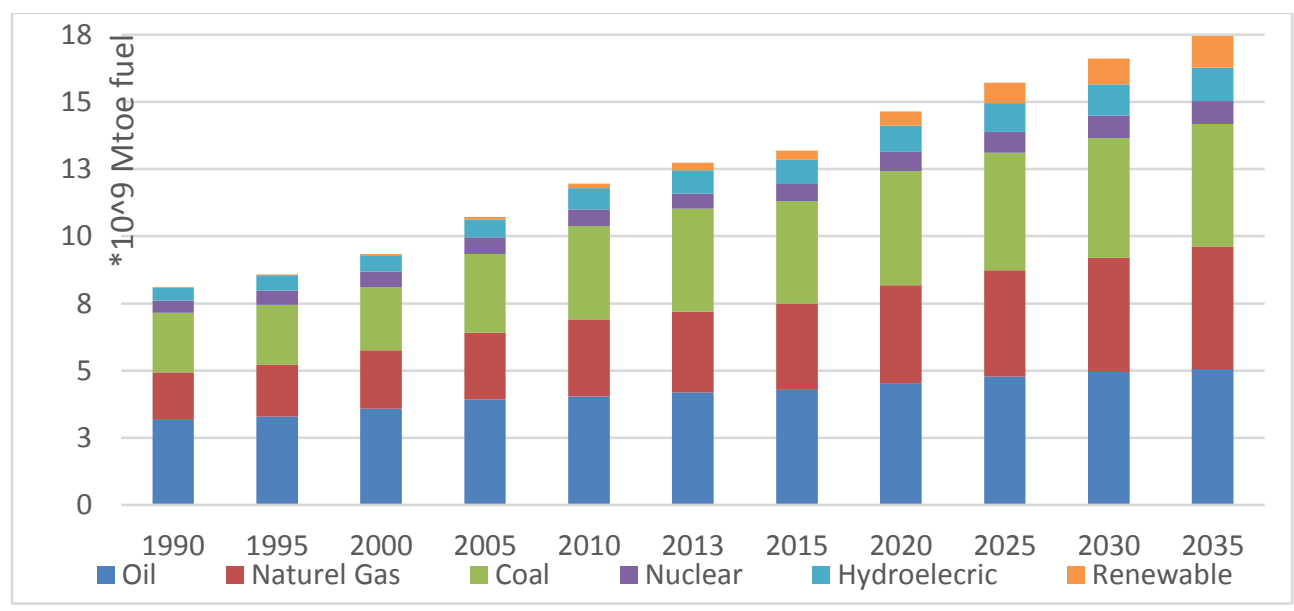

Figure 1. Produced power by plant [1] (1 Mtoe = $11630 \mathrm{GWh})$

This paper was recommended for publication in revised form by Regional Editor Kwok-wing Chau ${ }^{1}$ Naval Architecture and Maritime Faculty, Yildiz Technical University, İstanbul, Turkey

${ }^{*}$ E-mail address: asinan@yildiz.edu.tr 
Bresolin et al. [2] aimed to simulate the partial load characteristic with different control system (sliding pressure, throttling valve and nozzle valve control systems) of a steam turbine. In order to this, the inlet pressure which was calculated with respect to Schegliáiev and Stodola models where pressure is as a function of flow rate. The analyses showed that Schegliáiev and Stodola's models results were close and the operational modes by valves establishes theoretical limits of operation for steam turbines. Moreover, the best control system type is depended on turbine load and the sliding pressure control is better adapted to higher loads.

An analytical approach was developed by Weir [3] is expressed the compatibility between the enthalpy balances of cycle and flow characteristics of stage groups which is based on Stodola's Ellipse Law and uses a rapidly convergent iterative technique to estimate of steam turbine performance at partial loads.

Off-design steam pressures of a multistage turbine at a cogeneration plant model was investigated and criticized with respect to the Law of Ellipse by Cooke [4] and this study has shown that the Constant Flow Coefficient is a special case of generalized Law of Ellipse.

Petrovic and Riess [5] presented a method which is based on finite element procedure and the throughflow theory for flow calculation in large steam turbines. The method was adapted to the three stages low pressure turbine in the $165 \mathrm{MW}$ power plant which the flow field and performance over a wide range of mass flow and input pressure are calculated. The results showed that changing of flow field and performance of the first two stages are very little at operating conditions but the efficiency and internal work of the last stage are zero at $35 \%$ load.

Herzog et al. [6] have done a study to predict and explain the high pressure steam turbine behavior which helps the producer to take precautions to reduce both economic and technical risks because of the windage loses that occurs due to the bigger size of turbine blade and changing of the electricity demand. The study has analyzed the measurement of flow field at low Mach number for a four stages turbine in order to have better understanding about turbine aerodynamics and operation characteristics at partial load conditions. As a result experimental and numerical data has compared and a seven stage turbine was modeled.

Gerolymos and Hanisch [7] has developed a 3D flow calculation program which based on a multistage (four stages) turbine and its analysis with 3D averaged Favre-Reynolds-Navier-Stokes (RaNS) equations using the Launder-Sharma turbulence closure at partial loads to build up a flow model and explain turbo machinery characteristics at different conditions. The computation models the eight blade rows, including the tip clearance gaps of the rotors, using a 6x106 points grid, and computes the time-averaged flow using mixing planes between rows. After validating the method at different operating conditions a computation was run at reduced mass-flow conditions at the design speed and the results were compared to understand the multistage flow structure at these conditions. The calculations revealed that bigger flow separation has been occurred because of radial vortex over the concave side of the last stator at partial loads operating conditions. The radial vortex drug up to flow and so the flow inside of the channels was blockaged and turbine case damaged.

He [8] studied the effect of unsteady flow because of partial load conditions on the aerodynamic performance of multistage turbines and also has developed a 3D Navier-Stokes method and has made a comparison between the variable forces over the blades and experimental results for a single-stage for partial expansions.

Stastny et al. [9] published a report examining the relationship between turbine blade and flow field at partial load conditions. At off-design conditions, changing of velocity vectors at inlet section were calculated along the operation time and the results were compared with experimental data. The results showed that flow separation on the leading edge occurs at off-design conditions and this situation would lead to an increase of kinetic energy losses. Moreover, distribution of pressure over the profile surface gives some information about flow separation.

Mandal [10] has developed software to predict the performance of steam turbines at partial load conditions. In developing this software, some of the parameters that cause partial load conditions (flow rate, steam initial parameters, the condenser pressure and turbine speed change) have been considered however, pressure and flow changes turbine that may occur in extraction turbines and quality of steam at back stages of turbine were not considered. Although this software gives actual results for both high and intermediate pressure turbine, cannot give good results for low pressure turbines.

Bhattacharya [11] investigated the causes of partial load conditions and the effects of steam extracting from interstage of turbines and actual operating conditions have occurred in all types of turbine and has developed Mandal's study [10] by adding steam quality, turbine loses, adding sub-programs and optimization methods. 
Many experimental and numerical studies have done to analyze of steam turbine isentropic efficiency at partial load conditions. In this study, effects of different flow rate on steam turbine isentropic efficiency and power plant performance have analyzed.

\section{THERMODYNAMIC MODEL and OFF-DESIGN CONDITIONS}

Steam power plants are operated by Rankine cycle which includes steam boilers, steam turbines, condensers, heat exchangers, pumps and valves. Net produced work from the cycle and thermal efficiency highly depend on the chemical values of the burned fuel, boiler efficiency, the consuming energy on the condenser and pump(s) and isentropic efficiencies of steam turbine(s) and pump(s). Any pressure, temperature and flow rates changing at the inlet and/or outlet conditions will affect the both turbine isentropic efficiency and thermal efficiency.

The case power plant is located in Marmara region as two units. It produces $160 \mathrm{MW}$ per unit with $37 \%$ efficiency. It has 4 LP FWHs and 2HP FWHs, 3 impulse steam turbines which have 13, 10 and 5 stages, a boiler, condenser, degasifier, pumps in a unit, Figure 2.

Steam turbine is a heat engine that converts heat energy of the high temperature and pressure steam to kinetic energy and then kinetic to mechanical energy in two stages and/or electrical energy with alternators.

The maximum efficiency conditions, which the specific heat for each produced power is minimum, are also corresponding the most economical condition is called turbine operating conditions or turbine design conditions. Therefore, the maximum thermal efficiency conditions have to take into account while steam turbines design. In order to increase the efficiency, steam turbine capacities have to determine wide range of values between full load and zero load conditions [13].

Turbines are designed and manufactured taking into consideration some special conditions. Turbine blade profile and the geometric dimensions of each section are designed to take into consideration some parameters. Such as, turbine inlet and outlet parameters (pressure and temperature), specific steam flow rates, the current enthalpy drops, specific condenser pressure, specific extraction steam rates and the grid frequency are determined for specific conditions. In addition, the rotor diameter, height of the first and last blades, the number of stages and the thermodynamic cycle of system are also used to determine the design conditions.

Off-Design conditions can be created by many internal and external factors. Although the internal factors are generally controllable, it is very difficult to control the external factors. Some conditions that cause the offdesign conditions and reduce the turbine performance are changing of the inlet properties of the steam turbine, grid frequency, the condenser pressure and the performance of the feed water heater; partial arc, deformation of steam path and operating at partial loads [11]. Although the internal and external losses are minimum at design conditions, while operating time, it is almost impossible to work with design parameters at real working conditions which occur out of control.

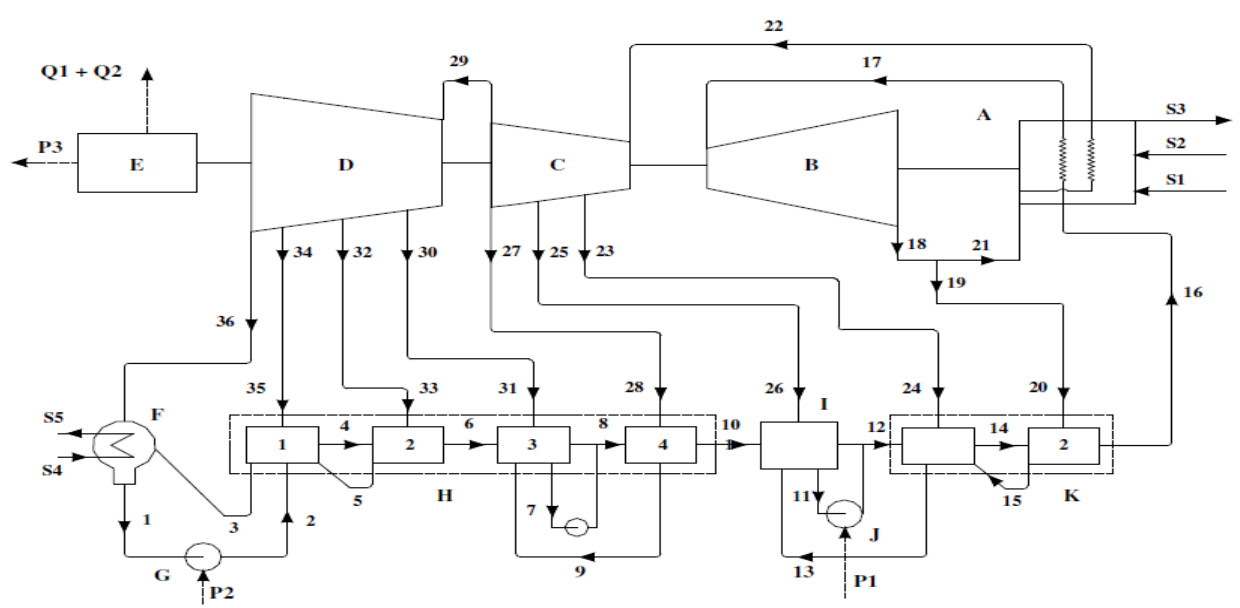

Figure 2. Case power plant [12] 


\section{Part Load Conditions}

Partial load conditions may occur energy demand variations, plant maintenances and repair so it is important to control steam flow. Partial load control can be arranged with two ways. The first is throttling governing which controls the system by changing turbine inlet pressure. If steam pressure decreases the steam flow rate and temperature are also decrease so in this system loses will be much more. The second system is nozzle governing which changes the flow rate at constant turbine inlet pressure and temperature. The second control method is much more efficient and so more common.

The steam flow rate is arranged by governors or check valves at different loads. While turbine inlet flow rate decreases the turbine inlet pressure also decreases (Ellipse Law). However, thermal efficiency and turbine isentropic efficiencies are highly depend on the pressure drops, that's way turbine inlet pressure keep constant even if flow rate changes.

Produced power is proportional with the steam flow rate and heat drop of steam turbine so this make possible to arrange power by changing this parameters [15] and sliding pressure boilers can also be used to governed the load.

\section{RESULTS AND DISCUSSION}

Performance calculations at partial loads have done with guaranteed pressure, temperature and flow rates values for $100 \%, 80 \%$ and $60 \%$ loads which were obtained from the plant manufacturer.

\section{Pressure and Temperature Variations}

Design inlet pressure of high pressure turbine does not change while the load is changing but extraction and outlet pressures of back pressure, extraction and condensing turbines vary in proportion with the load. Therefore, this will reduce the turbine and plant efficiencies. Temperature and pressure variations at a HP turbine stages for different loads are shown in Figure 4.

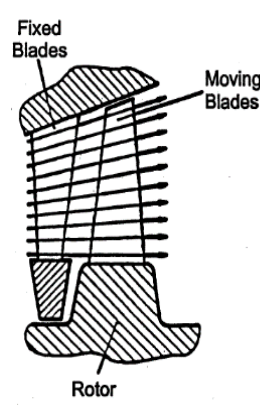

Full Load Operation

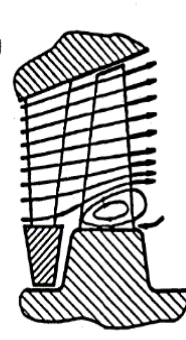

Low Load Operation

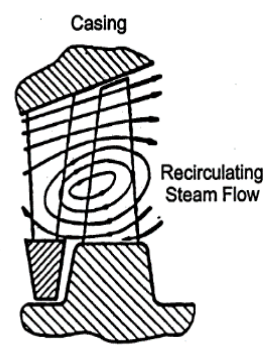

No Load Operation

Figure 3. Partial load conditions at turbine blade [14]

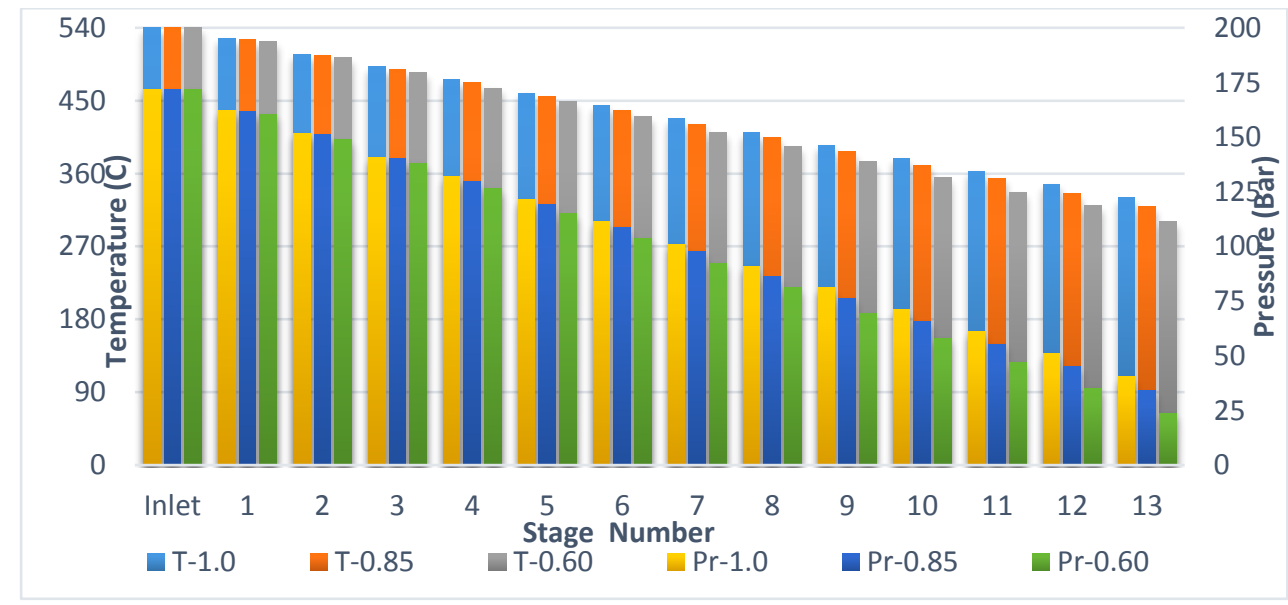

Figure 4. Temperature \& Pressure variations in turbine stages at partial loads 


\section{Specific Enthalpy Drops and Power Variations}

Specific enthalpy values change with load variation at HP turbine stages which can be seen in Figure 5. The amount of enthalpy drop and also theoretical work of HP turbine increases because of Inlet pressure and temperature generally keep constant but outlet pressure changes in proportion with load variation. However, amount of theoretical enthalpy drop and work of IP turbine and LP turbine keep almost constant, except for very low load.

The power generated from the plant depends on the enthalpy drop and flow rate of turbine are main parameters to determine the plant load. Despite the increasing amount of the specific work, the generated power decreases because of the decreasing of flow rate with variation to load at the high pressure turbine. In addition to this, the enthalpy drops of the intermediate and low pressure turbines are nearly constant but generated power is also decreasing with the reduction of flow rate. The generated power from the turbines at partial loads are shown in the Figure 6.

$W=\left(h_{\text {in }}-h_{\text {out }}\right)$

$P=\dot{m} W$

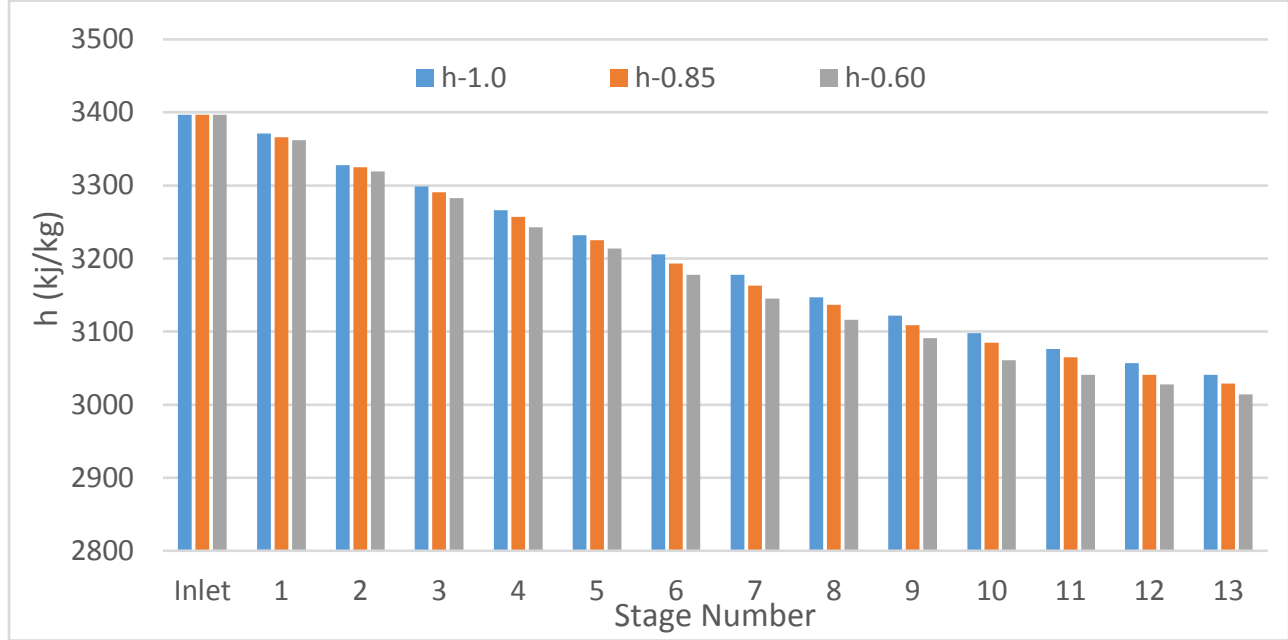

Figure 5. Specific enthalpy variation at turbine stages at partial loads

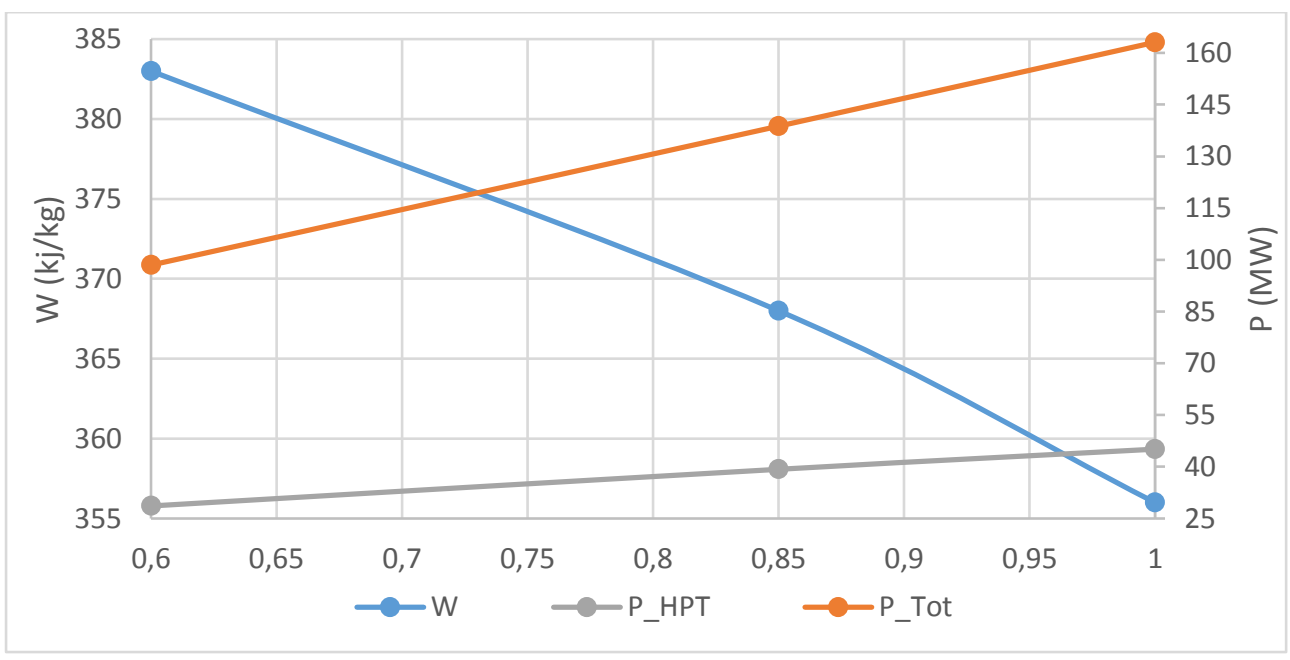

Figure 6. Specific work and turbine power variations at partial loads 


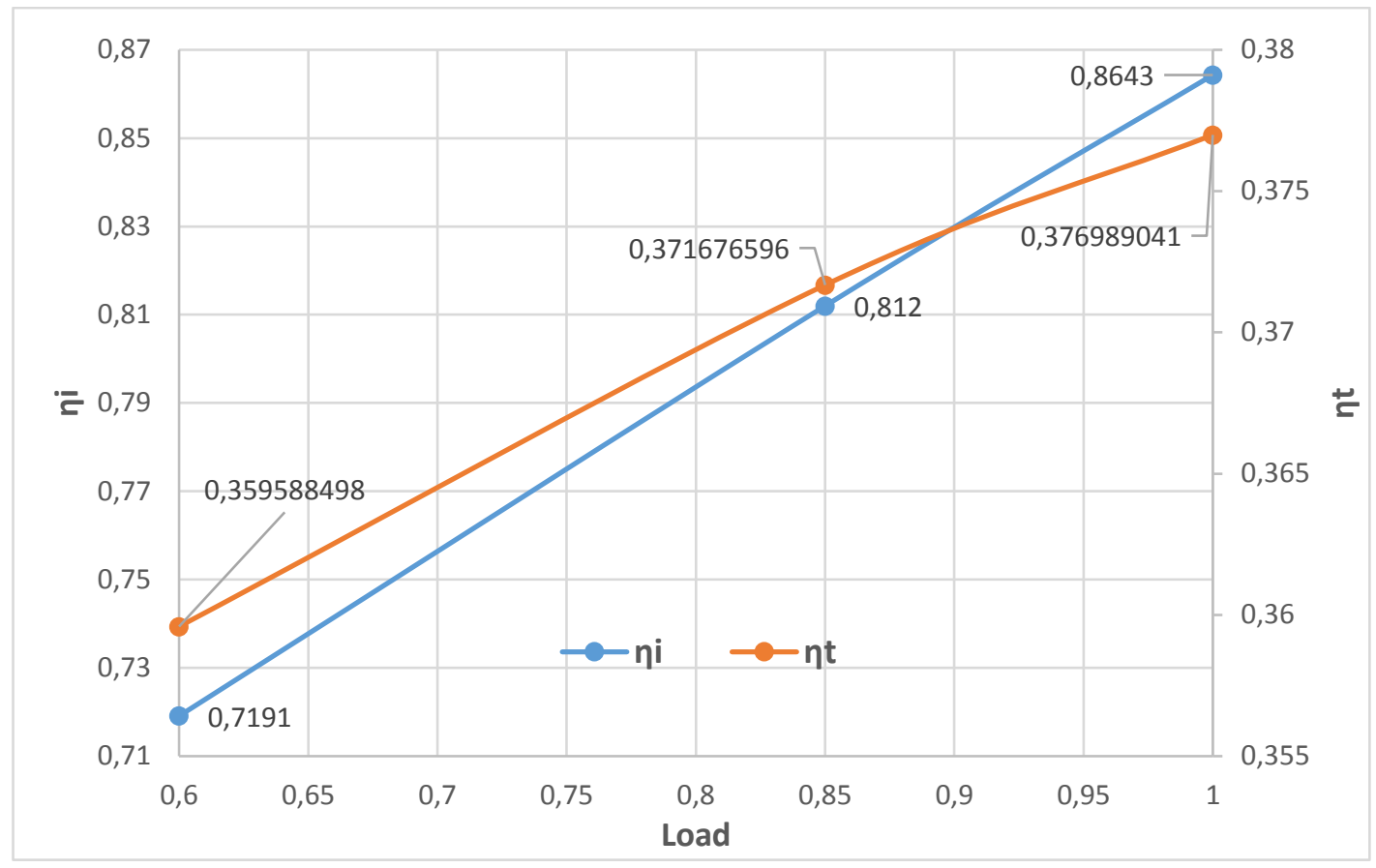

Figure 7. Isentropic efficiency of turbine and plant thermal efficiency variations at partial loads

\section{Internal Efficiency of a HP Steam Turbine}

How the performance of a steam turbine has changed at partial load conditions can be explained on the basis of the relationship between steam pressure, temperature and flow rate. Power output rate, the relationship between the enthalpy drop and the pressure ratio, Law of Ellipse or Stodola's Cone and Schegliaev model can describe this relationship.

Turbine indicated efficiency is an important performance parameter which can be calculated from turbine inlet and outlet parameters that guaranteed by turbine producer or the difference between theoretical enthalpy drops and loses for each stage. In this study, high pressure turbine indicated efficiency is calculated with turbine producer data, Figure 7

$\eta_{i}=\frac{h_{\text {in }}-h_{\text {out }}}{h_{\text {in }}-h_{\text {out }, s}}$

\section{Thermal Efficiency of Power Plant}

Thermal efficiency, which describes in Eq. 1 the ratio of net work to heat, of a system does not only depend on an equipment performance, it depends on the performance of all the equipment that create the plant such as boiler, steam turbines, condenser, pumps and heat exchangers for case plant.

$\eta_{t}=\frac{W_{\text {net }}}{Q_{\text {in }}}$

The results show that thermal and produced power decrease as the load decreases, Figure 7. This means that unit electricity costs will increase and the economic criteria will get worse. Moreover, most of the system equipment will also operates off design conditions that damage them.

\section{CONCLUSION}

In the first part of this study, a short review about turbine performance at partial loads and off design conditions has been done and then general information about power plants was given. In third part of the study, operation principles, design and off design conditions of steam turbines have investigated/introduced and then performance analysis of a high pressure steam turbine and a power plant have done at off design conditions for a real plant. Performance calculations at partial loads have done with guaranteed pressure, temperature and flow 
rates values which were obtained from the plant manufacturer. Analyzes showed that both turbine and the power plant performances reduce at partial load conditions. In order to obtain exact results, a comprehensive measurement system and standards must be improved for all type of turbine and control systems.

\section{ACKNOWLEDGEMENT}

This paper was compiled from presented master thesis by Karakurt [16] at Graduate School of Natural and Applied Sciences of Yıldız Technical University. Authors thank to Prof. Bahri ŞAHIN for his advice and support.

\section{NOMENCLATURE}

$\begin{array}{ll}\eta & \text { Efficiency } \\ \text { FWH } & \text { Feed water heater } \\ \text { h } & \text { Enthalpy } \\ \text { HP } & \text { High pressure } \\ \text { IP } & \text { Intermediate pressure } \\ \text { LP } & \text { Low pressure } \\ \text { Q } & \text { Heat } \\ \text { P } & \text { Power } \\ \text { Pr } & \text { Pressure } \\ \text { T } & \text { Temperature } \\ \text { W } & \text { Specific work } \\ \text { Subscripts } & \\ \text { i } & \text { Indicated } \\ \text { in } & \text { Inlet } \\ \text { out } & \text { Outlet } \\ \text { s } & \text { Ideal } \\ \text { t } & \text { Thermal } \\ \text { T } & \text { Turbine } \\ \text { Tot } & \text { Total }\end{array}$

\section{REFERENCES}

[1] “BP Energy Outlook 2035,” British Petroleum, Statistical Review, 2015.

[2] C. S. Bresolin, P. S. Schneider, H. A. Vielmo, and F. H. R. França, “Applications of Steam Turbines Simulation Models in Power Generations Systems,” Eng. Térmica Therm. Eng., vol. 5, no. 1, pp. 73-77, Jul. 2006.

[3] C. D. Weir, "An Analytical Approach to the Estimation of the Performance of Steam Turbine Cycles OffDesign,” Proc. Inst. Mech. Eng. Part J. Power Energy, vol. 199, no. 1, pp. 33-43, Feb. 1985.

[4] D. H. Cooke, "Modeling of Off-Design Multistage Turbine Pressures by Stodola's Ellipse." Bechtel Power Co., Nov-1983.

[5] M. Petrovic and W. Riess, "Off-design flow analysis of low-pressure steam turbines," Proc. Inst. Mech. Eng. Part J. Power Energy, vol. 211, no. 3, pp. 215-224, May 1997.

[6] N. Herzog, M. Binner, J. R. Seume, and K. Rothe, "Verification of Low-Flow Conditions in a Multistage Turbine," pp. 563-574, Jan. 2007.

[7] G. A. Gerolymos and C. Hanisch, "Multistage three-dimensional Navier-Stokes computation of offdesign operation of a four-stage turbine,” Proc. Inst. Mech. Eng. Part J. Power Energy, vol. 213, no. 4, pp. 243261, Jun. 1999.

[8] L. He, "Computation of unsteady flow through steam turbine blade rows at partial admission," Proc. Inst. Mech. Eng. Part J. Power Energy, vol. 211, no. 3, pp. 197-205, May 1997.

[9] M. Št'astný, P. Šafařík, I. Hořejší, and R. Matas, "Flow around the sections of rotor blading of a turbine stage with relatively long blades at off-design conditions," Proc. Inst. Mech. Eng. Part J. Power Energy, vol. 211, no. 3, pp. 207-213, May 1997.

[10] A.. Mandal, "Off design performance prediction of steam turbines," Department Of Mechanical Engineering Indian Institute Of Technology, Delhi, Project Report, 2005. 
[11] S. Bhattacharya, "Prediction Of Off-Design Performance Of Steam Turbines and Extraction Steam Flow Optimization,” Department Of Mechanical Engineering Indian Institute Of Technology, Delhi, Project Report, 2007.

[12] Z. Oktay, "Investigation of coal-fired power plants in Turkey and a case study: Can plant," Appl. Therm. Eng., vol. 29, no. 2-3, pp. 550-557, Feb. 2009.

[13] P. Shlyakhin and P. N. Shl'iakhin, Steam Turbines: Theory and Design. University Press of the Pacific, 2005 .

[14] “Turbine and Auxiliaries.” CANTEACH, Jul-1994.

[15] A. Özge, Marine Steam Turbines and Plants. İTÜ, 1989.

[16] A. S. Karakurt, "Analysis of the part load conditions effects on turbine performance," Master Thesis, Y1ldız Technical University, İSTANBUL, 2012. 